\title{
42
}

\section{Bio querbeet: von Krebsen bis zum Kleidungsstück (Buchstaben-Anzahl)}

Trage die passenden Begriffe zu den folgenden acht Definitionen in dasRasterein. DieBuchstabenanzahleines gefundenen Begriffs verrät dir, welcher Lösungsbuchstabe unten einzutragen ist (siehe Buchstabenschlüssel). Zum Beispiel „Ulna“: 4 Buchstaben, ergibt also ein R.

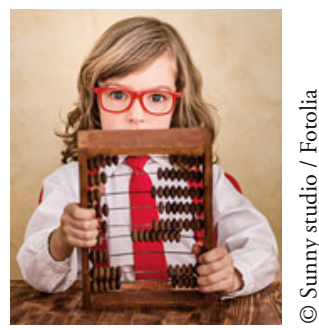

\section{Definitionen}

(a) Kopf der Insekten, (b) Elle (lat.), (c) Unterkiefer der Gliederfüßer, (d) Mantel der Manteltiere, (e) Erbanlage, (f) Luftröhre, (g) die Hummeln (lat.), (h) Organismus, der von einem Parasiten befallen ist

\section{Buchstaben-Schlüssel}

3 Buchstaben $=\mathbf{C}, 4$ Buchstaben $=\mathbf{R}, 5$ Buchstaben $=\mathbf{U}$

6 Buchstaben $=\mathbf{E}, 7$ Buchstaben $=\mathbf{H}, 8$ Buchstaben $=\mathbf{B}$

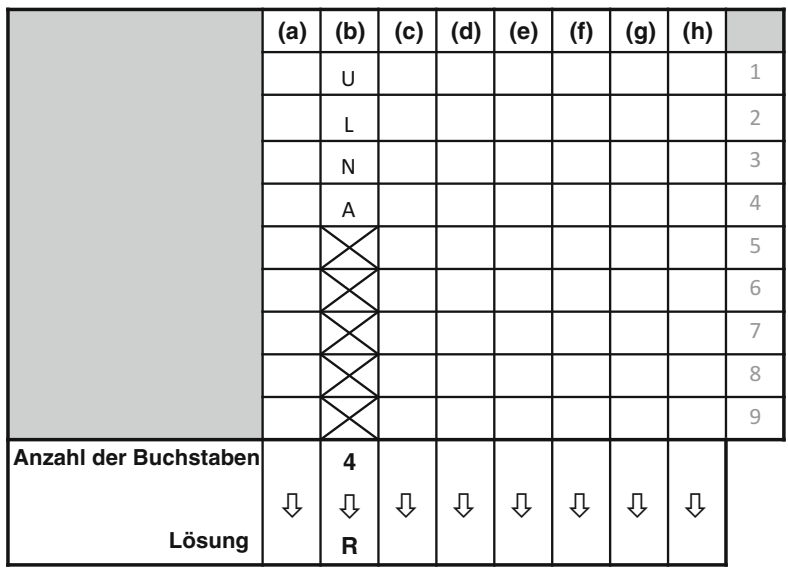

(C) Springer-Verlag Berlin Heidelberg 2016 C. Reinbold, Fetthenne, Moderlieschen, Warzenbeißer, DOI 10.1007/978-3-662-52817-4_42 